\title{
Role of metabolic enzymes in resistance to chlorpyrifos-methyl in the cowpea aphid, Aphis craccivora (Koch)
}

\author{
El-Sayed Mohammad Soliman Mokbel ${ }^{1 *}$, Eman Saed Hassan Swelam², \\ Eman Mohamed Mostafa Radwan ${ }^{1}$, Mohammed Abd-Elhady Kandil ${ }^{2}$ \\ ${ }^{1}$ Department of Standard Rearing, Central Agricultural Pesticides Laboratory, Agriculture Research Center, 12618 Giza, Egypt \\ ${ }^{2}$ Department of Economic Entomology and Pesticides, Faculty of Agriculture, Cairo University, 12613 Giza, Egypt
}

Vol. 57, No. 3: 275-280, 2017

DOI: 10.1515/jppr-2017-0039

Received: June 02, 2017

Accepted: September 01, 2017

*Corresponding address: saydmokbel@yahoo.com

\begin{abstract}
The cowpea aphid, Aphis craccivora management relies mainly on chemical control. As a result extensive and repeated treatment of insecticides has led to the development of aphid resistance to commonly used insecticides. To investigate chlorpyrifos-methyl resistance in A. craccivora, a field strain was selected for 24-generations to achieve a resistance factor of 82.3 fold compared with a susceptible strain. In the resistant strain, malathion and lambda-cyhalothrin exhibited obvious cross-resistance; while fenvalerate and dinotefuran showed moderate cross-resistance. In contrast, slight or no cross-resistance was obtained with the other tested insecticides. To investigate metabolic resistance mechanisms, integration of biochemical and synergism assays was conducted. Results showed the key role of esterase (EST) and mixed function oxidases (MFO); however, glutathione-s-transferase (GST) contributed less to resistance. Cross-resistance studies showed the need for rotation with non-cross resistant insecticides as a resistance management tactic.
\end{abstract}

Key words: Aphis craccivora, chlorpyrifos-methyl, metabolic enzymes, resistance

\section{Introduction}

The cowpea aphid, Aphis craccivora (Koch) (Homoptera: Aphididae) is an important legume insect pest in Egypt (El-Ghareeb et al. 2002). Aphid infestation causes major yield losses as a result of their deleterious effects through either honeydew excretion or viruses' transmission (Laamari et al. 2008). Pest management relies mainly on insecticide applications. Organophosphate is a main class of insecticides which is used extensively due to its favorable characteristics (Costa 2006). Intensive and repeated use of insecticides in agriculture has generated a strong selection leading to resistance in over 600 arthropod species including aphid (Anonymous 2009; Mokbel and Mohamed 2009). Insecticide resistance hinders seriously agricultural pest control (Andrew et al. 2006). Risks associated with the development of new insecticides have led to the need to preserve sustainable efficacy of used active ingredients.

Strategies must be developed to preserve the efficiency of these insecticides (Wang et al. 2002). Means of resistance management can be designed by investigating cross-resistance and resistance mechanisms (Criniti et al. 2008). Investigating characteristics of resistance is necessary to develop strategies to manage resistance. Therefore the current study investigated the development of chlorpyrifos-methyl resistance, crossresistance to other insecticides and explores the role of detoxifying enzymes in resistance. 


\section{Materials and Methods}

\section{Chemicals and insecticides}

Piperonyl butoxide (PBO), tribufos S,S,S-tributyl phosphorothioate (DEF), glutathione (GSH) and 1-chloro2,4-dinitrobenzene (CDNB) were obtained from SigmaAldrich. a-naphthyl acetate was obtained from MPBio. Diethyl maleate (DEM) was obtained from Alfa-Aesar. All chemicals were technical grade (99\%). Insecticides used in the current work are shown in Table 1.

\section{Insects}

Two strains of the cowpea aphid were utilized. The laboratory strain was acquired from the Plant Protection Research Institute and reared free from insecticide exposure under constant laboratory conditions $\left[22 \pm 2^{\circ} \mathrm{C}, 70 \pm 5 \%\right.$ relative humidity $(\mathrm{RH})$ and $12: 12$ light-dark photoperiod]. Aphids were reared on broad bean seedlings (Vicia fabae) grown in plastic pots (15 cm diameter) until needed. This strain was considered as the susceptible (S) strain. The other strain was the chlorpyrifos-methyl resistant (R) strain. This strain was initially collected from faba bean fields in Sharkia Governorate, Egypt, and had been previously exposed to various recommended insecticides belonging to different classes. Selection for chlorpyrifos-methyl resistance was accomplished by utilizing the dipping technique according to Guo et al. (1996). Faba bean seedlings were infected with apterous adults of aphids for $24 \mathrm{~h}$ before treatment. Plants bearing aphids were dipped in the desired concentration for $10 \mathrm{~s}$. They were allowed to air dry for around $1 \mathrm{~h}$, and then set in the rearing room. The surviving aphids were placed on new plants and kept until apterous adults of the next generation were used for bioassay.

\section{Bioassay}

Leaf-dip bioassay according to Moores et al. (1996) was used. Faba bean leaves were dipped in insecticide aqueous solution for about $10 \mathrm{~s}$, and left to dry on a paper towel. Then, the leaves were placed upside down on an agar bed in Petri dishes $(60 \mathrm{~mm}$ diameter). Ten apterous adults were placed on the treated leaf for each replicate. Leaves dipped in water served as control. Five replicates (i.e. 50 insects) were used per each insecticide concentration, and 5-7 concentrations were used per each insecticide. Petri dishes containing aphids were kept in the rearing chamber until mortality was recorded after $48 \mathrm{~h}$. The resistance ratio (RR) was calculated by dividing $\mathrm{LC}_{50}$ of R-strain/ $/ \mathrm{LC}_{50}$ of S-strain. Cross-resistance was examined against the other tested insecticides by the aforementioned leafdipping bioassay. $\mathrm{LC}_{50}$ values from both $\mathrm{S}$ and $\mathrm{R}$ strains were converted to the $\mathrm{RR}$ as mentioned above.

\section{Synergism study}

To investigate the role of detoxification enzymes in causing resistance the following synergists were used: DEF (esterase inhibitor), DEM as glutathione-s-transferase (GSTs) inhibitor and PBO (oxidase inhibitor). A constant concentration of each synergist (maximum

Table 1. List of insecticides with their trade names, active ingredients, IRAC classification and their producers

\begin{tabular}{|c|c|c|c|c|}
\hline $\begin{array}{l}\text { Active ingredient } \\
\text { (common name) }\end{array}$ & Trade name & Manufacturer & Chemical group & IRAC MoA \\
\hline Chlorpyrifos-methyl & Reldan 50\% EC & Agrin Serve & organophosphates & Group 1B \\
\hline Imidacloprid & Best $50 \%$ WP & Syngenta & neonicotinoid & Group 4A \\
\hline Acetamiprid & Mospilan 20\% SP & Nippon Soda & neonicotinoid & Group 4A \\
\hline Dinotefuran & Ocean $20 \%$ SG & Mitsui Chem. Inc. & neonicotinoid & Group 4A \\
\hline Thiamethoxam & Actara $25 \%$ WP & Syngenta & neonicotinoid & Group 4A \\
\hline Malathion & Malason 57\% EC & Ficom Organics & organophosphates & Group 1B \\
\hline Pirimicarb & Aphox 50\% DG & Syngenta & carbamates & Group 1A \\
\hline Carbosulfan & Marshal 25\% WP & FMC & carbamates & Group 1A \\
\hline Lambda-cyhalothrin & Lambda 5\% EC & Barghat & pyrethroids & Group 3A \\
\hline Es-fenvalerate & Sumi-gold 10\% EC & Sumitomo & pyrethroids & Group 3A \\
\hline Pymetrozine & Chess $25 \%$ WP & Syngenta & pyridine azomethine derivatives & Group 9B \\
\hline Diafenthiuron & Polo $50 \%$ SC & Syngenta & diafenthiuron & Group 12A \\
\hline
\end{tabular}


concentration of synergist that showed no observed mortality in the susceptible strain) was obtained by adding synergists to the prepared insecticide concentrations to get an insecticide + synergist solution. Faba bean leaves were dipped in the insecticide + synergist solution for $10 \mathrm{~s}$. Leaves dipped in the synergist alone served as control. The synergistic ratio (SR) was calculated as follow:

$$
\begin{gathered}
\mathrm{SR}=\mathrm{LC}_{50} \text { of insecticide alone } / \mathrm{LC}_{50} \text { of insecticide }+ \\
+ \text { synergist. }
\end{gathered}
$$

\section{Biochemical assays}

Total esterase activity was measured according to Van Asperen (1962) with $\alpha$-naphthyl acetate ( $\alpha$-NA) as a substrate with the modification of Cao et al. (2008). Fifty wingless adults from each strain were homogenized in $1 \mathrm{ml}$ of ice-cold phosphate buffer $(0.04 \mathrm{M}$, $\mathrm{pH}$ 7.0). The homogenate was centrifuged at $12,000 \mathrm{~g}$ for $15 \mathrm{~min}, 4^{\circ} \mathrm{C}$. The resulting supernatants were diluted 20-fold with the homogenization buffer and used for subsequent esterase activity assay, then stored at $20^{\circ} \mathrm{C}$. The $\alpha$-naphthyl acetate concentration was $0.3 \mathrm{mM}$, diluted from their respective $0.03 \mathrm{M}$ stock. The assay mixture contained $50 \mu \mathrm{l}$ enzyme preparation, $450 \mu \mathrm{l}$ $0.04 \mathrm{M}$ phosphate buffer and $1.80 \mathrm{ml} 0.3 \mathrm{mM}$ substrate solution. The reaction was stopped by adding $0.9 \mathrm{ml}$ of stop solution (two parts of $1 \%$ Fast Blue BB and five parts of $5 \%$ sodium dodecyl sulfate). Incubation at $30^{\circ} \mathrm{C}$ for $15 \mathrm{~min}$ at room temperature allowed color development. The absorbance was measured at $600 \mathrm{~nm}$ for the hydrolysis of $\alpha$-NA. Mean levels of total esterase activity were calculated based on protein content and a-naphthol standard curves.

Glutathione-s-transferase (GST) activity was determined according to Habig et al. (1974). 1-chloro2,4-dinitrobenzene (CDNB) was used as the substrate in ultraviolet (UV) semi-micro cuvettes $(4 \mathrm{ml})$ by sequential addition of $0.1 \mathrm{M}$ phosphate buffer $\mathrm{pH} 6.5$ $(1.78 \mathrm{ml})$, enzyme preparation $(0.1 \mathrm{ml}), 50 \mathrm{mM}$ of reduced GST solution in buffer $(0.1 \mathrm{ml})$ and $50 \mathrm{mM}$ CDNB solution in acetonitrile $(0.02 \mathrm{ml})$, giving $2 \mathrm{ml}$ final volume of the incubation mixture. Enzyme activity was determined by monitoring continuous changes in absorbance at $430 \mathrm{~nm}$ for $3 \mathrm{~min}$ at $25^{\circ} \mathrm{C}$ with a spectrophotometer.

\section{Statistical analysis}

Mortality was corrected using Abbott's formula (Abbott 1925) and data were analyzed by probit analysis (Finney 1971) using the software package EPA probit analysis version 1.5. Mean enzyme activities recorded from the $\mathrm{R}$ strain were compared with those from the $\mathrm{S}$ strain colony

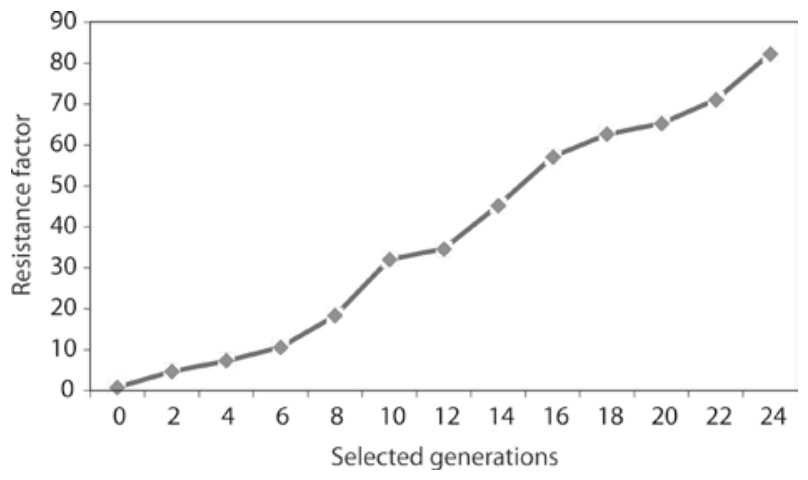

Fig. 1. Resistance development rate to chlorpyrifos-methyl in Aphis craccivora which selected every generation for a total of 24 generations

with the Student's t-test using SPSS version 19. Significance was accepted at $\alpha=0.05$ in the Student's t-test.

\section{Results}

\section{Selection for resistance}

Data in Figure 1 revealed that the initial $\mathrm{LC}_{50}$ value was $0.18 \mathrm{ppm}$ (for the 1 st generation); resistance level was increased proportionally by continuous selection. Resistance ratio increased from 0.78 fold in the 1 st generation to 82.3 fold after the 24 th generation. Tenfold resistance required six successive generations. Resistance increased gradually until the 12th generation and further elevated dramatically up to the 24th generation.

\section{Cross-resistance study}

Results summarized in Table 2 exhibited cross-resistance against the organophosphate malathion (15.62 fold) and the synthetic pyrethroid, lambda-cyhalothrin (21.4 fold). Es-fenvalerate showed moderate cross-resistance with a resistance ratio of 8.8 fold. On the other hand, carbamate insecticides (pirimicarb and carbosulfan) showed no or slight cross-resistance, 1.06 fold and 3.51 fold, respectively. The neonicotinoid, acetamiprid, thiamethoxam, dinotefuran and imidacloprid showed negative or low RR with values of 1.3, 0.89, 5.53 and 3.03 fold, respectively. Similar trends were noticed with pymetrozine and diafenthiuron which exhibited resistance ratios of 1.43 and 3.06 fold, respectively.

\section{Enzymes and synergism assay}

Figure 2 presents the mean activities of esterase in the susceptible and resistant strains. By using the model 
Table 2. Cross-resistance of chlorpyrifos-methyl (R strain) of Aphis craccivora to the tested insecticides

\begin{tabular}{llcc}
\hline \multicolumn{1}{c}{ Insecticide } & \multicolumn{1}{c}{$\begin{array}{c}\text { Susceptible } \\
\text { strain LC }(95 \% \mathrm{CL})\end{array}$} & $\begin{array}{c}\text { Resistant } \\
\text { strain LC }\end{array}$ (95\% CL) & $\begin{array}{c}\text { Resistant } \\
\text { ratio (RR) }\end{array}$ \\
\hline Imidacloprid & $0.77(0.49-1.10)$ & $2.34(1.46-3.73)$ & 3.03 \\
Acetamiprid & $0.13(0.087-0.187)$ & $0.17(0.09-0.28)$ & 1.30 \\
Dinotefuran & $0.95(0.59-1.34)$ & $5.26(3.04-14.77)$ & 5.53 \\
Thiamethoxam & $0.44(0.29-0.60)$ & $0.39(0.10-0.85)$ & 0.89 \\
Malathion & $9.47(6.21-12.88)$ & $147.9(101.5-231)$ & 15.62 \\
Pirimicarb & $1.02(0.55-1.37)$ & $1.09(0.71-1.54)$ & 1.06 \\
Carbosulfan & $4.56(3.25-6.54)$ & $16.03(7.8-26.06)$ & 3.51 \\
Lambda-cyhalothrin & $0.007(0.00-0.019)$ & $0.15(0.07-0.32)$ & 21.40 \\
Es-fenvalerate & $0.15(0.11-0.19)$ & $1.32(0.73-2.33)$ & 8.80 \\
Pymetrozine & $6.12(4.18-9.14)$ & $8.79(4.42-14.46)$ & 1.43 \\
Diafenthiuron & $23.46(11.37-46.80)$ & $71.8(46.44-92.44)$ & 3.06 \\
\hline
\end{tabular}

$\mathrm{CL}$ - confidence limits

$R R=L C_{50}$ of selected strain/LC $C_{50}$ of susceptible strain

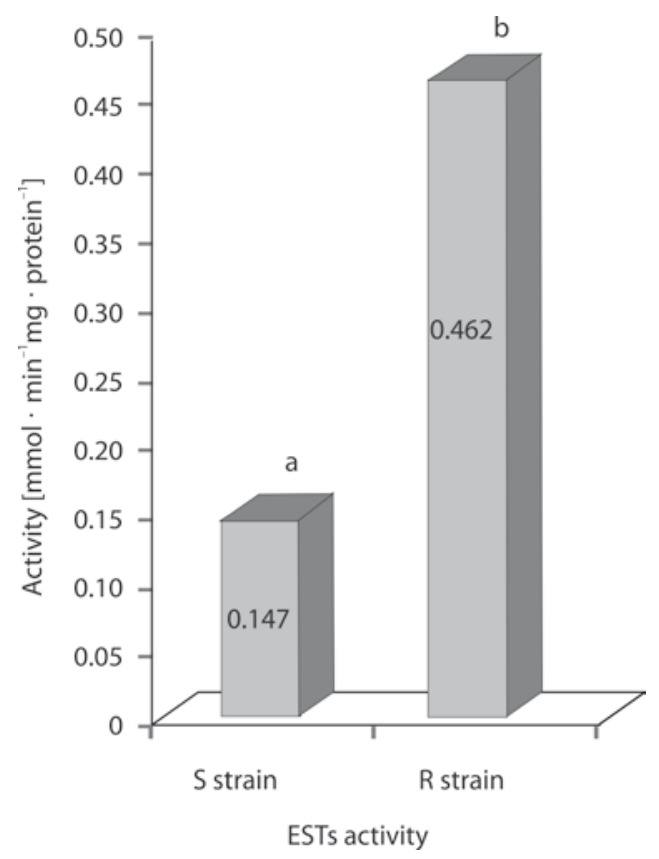

Fig. 2. Activity of esterases (ESTs) in susceptible (S strain) and chlorpyrifos-methyl resistant (R strain) of Aphis craccivora. Graph bars containing similar letters on the top are not significantly different $(p=0.05)$

substrate $\alpha-\mathrm{NA}$, esterase activity elevated (3.14 times) in R-strain compared with S-strain. Furthermore, Figure 3 showed that R-strain exhibited a slight change in glutathione-s-transferase activity with a ratio of 1.33 compared with $S$ strain. Results in Table 3 indicated that $\mathrm{PBO}$ showed a synergistic ratio value of 5.69 while DEF exhibited a synergistic ratio of 11.6 , in contrast DEM showed only a synergistic ratio value of 1.58 .

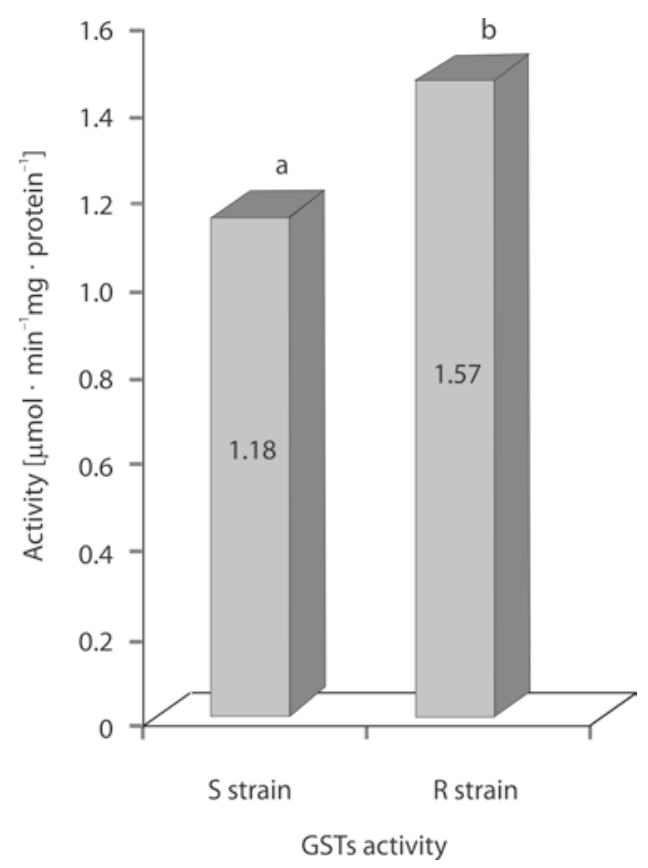

Fig. 3. Activity of glutathione-S-transferases (GSTs) in susceptible (S strain) and chlorpyrifos-methyl resistant (R strain) of Aphis craccivora. Graph bars containing similar letters on the top are not significantly different $(p=0.05)$

\section{Discussion}

In our study, laboratory selection with chlorpyrifos-methyl increased resistance level to approximately 10-fold after six generations and 82-fold after 24 generations. Our results are in harmony with Mokbel (2015) who found that the cowpea aphid had the potential to develop 
Table 3. Synergistic effect of piperonyl butoxide (PBO), tribufos $S, S, S$-tributyl phosphorothioate (DEF) and diethyl maleate (DEM) to (S strain) and chlorpyrifos-methyl (R strain) Aphis craccivora

\begin{tabular}{|c|c|c|c|c|c|}
\hline Strain & Treatment & Slope \pm SE & $\begin{array}{c}\mathrm{LC}_{50}\left[\mathrm{mg} \cdot \mathrm{I}^{-1}\right] \\
95 \% \mathrm{CL}\end{array}$ & $\begin{array}{c}\text { Synergistic } \\
\text { ratio (SR) }\end{array}$ & $\begin{array}{l}\text { Resistance } \\
\text { ratio (RR) }\end{array}$ \\
\hline \multirow{4}{*}{ S strain } & Alone & $2.03 \pm 0.40$ & $0.23(0.14-0.33)$ & - & - \\
\hline & $+\mathrm{DEF}$ & $1.33 \pm 0.24$ & $0.16(0.09-0.26)$ & 1.39 & - \\
\hline & $+\mathrm{PBO}$ & $1.46 \pm 0.25$ & $0.17(0.10-0.26)$ & 1.35 & - \\
\hline & + DEM & $1.53 \pm 0.31$ & $0.20(0.11-0.25)$ & 1.13 & - \\
\hline \multirow{4}{*}{ R strain } & Alone & $2.28 \pm 0.59$ & $18.9(12.75-24.97)$ & - & 82.30 \\
\hline & $+\mathrm{DEF}$ & $3.27 \pm 0.61$ & $1.63(1.33-2.07)$ & 11.60 & 7.09 \\
\hline & $+\mathrm{PBO}$ & $1.76 \pm 0.28$ & $3.32(2.39-4.70)$ & 5.69 & 14.46 \\
\hline & +DEM & $2.05 \pm 0.49$ & $12.02(10.34-16.21)$ & 1.58 & 52.26 \\
\hline
\end{tabular}

$\mathrm{CL}$ - confidence limits

$\mathrm{SR}=\mathrm{LC}_{50}$ of insecticide alone/LC $\mathrm{Lf}_{50}$ insecticide + synergist

$R R=L C_{50}$ of $R$ strain/LC $C_{50}$ of $S$ strain

resistance to chlorpyrifos-methyl. Selection with chlorpyrifos-methyl for 24 generations resulted in 105 fold resistance compared with the susceptible strain.

Although chlorpyrifos-methyl and malathion belong to the same class and are expected to share a common resistance mechanism, the $A$. craccivora resistant strain ( $\mathrm{R}$ strain) showed a lower resistance factor to malathion than that of chlorpyrifos-methyl. Similar findings were obtained with Oryzaephilus surinamensis. These differences were interpreted to result from the major differences in carboxylesterase isozymes between malathion and chlorpyrifos resistant strains (Lee and Lees 2001). Negative cross-resistance to thiamethoxam, pirimicarb, acetamiprid and pymetrozine may be due to the fact that these insecticides have different modes of actions. Although pirimicarb has a mode of action similar to organophosphates, it showed a unique mechanism of resistance (reduced sensitivity of acetylcholinesterase) (Kandil et al. 2017). Similar trends were found by Suzuki et al. (1993) who showed that there was no correlation between carboxylesterase activity and resistance to dimethyl carbamate in A. gossypii.

Integration between enzymes and synergism assays has a significant role in identifying metabolic resistance mechanisms. Metabolic resistance to organophosphates in aphids has been thought to be due to the elevated activity of a number of detoxification systems. It is generally expected that resistance to organophosphates is correlated with elevated esterase activity especially with the model substrate $\alpha$-naphthyl acetate (Devonshire 1977). It is noteworthy that our results indicated an elevation of esterase activity in the $\mathrm{R}$ strain about 3-fold more than that in the $\mathrm{S}$ strain. Moreover, synergism assay showed that esterase and monooxygenases, as metabolic enzymes, may play a vital role in chlorpyrifos-methyl resistance. Adding either DEF or PBO suppressed resistance from 82.3-fold to 7.9 and 14.46-fold, respectively. So, R strain switched to tolerance level by using esterase inhibitor. This means that esterase plays the key role in the resistance mechanism of $\mathrm{R}$ strain, followed by monooxygenases. The greater activity of detoxifying enzymes, particularly carboxylesterase has a significant role in endowing resistance to thiamethoxamin in the cowpea aphid (Abdallah et al. 2016). These results agree with Fouad et al. (2016) who found that esterase activity in three field populations of cowpea aphid was higher than in the susceptible strain. The activity ratios ranged from 4.3 to 7.8-fold. Moreover, these results agree with Kandil et al. (2013) who found that DEF and PBO had significant synergism in the acetamiprid-resistant strain of cowpea aphid with a synergism ratio of 3.74 and 8.3-fold, respectively. Also, Lee and Lees (2001) found elevated levels of carboxylesterase activity in O. surinamensis resistant to malathion and chlorpyrifos-methyl. The role of GST's in conferring insecticide resistance is mainly due to the conjugation to insecticides or their primary metabolites. Biochemical determination of GSTs activity or synergist assay showed slight differences in activity of GSTs in either R strain or S strain of the cowpea aphid (Fig. 3).

In conclusion, the current data revealed the potential of A. craccivora to develop resistance to chlorpyrifos-methyl. Negative cross-resistance to thiamethoxam, acetamiprid and pymetrozine makes it possible to use it in rotation with chlorpyrifos-methyl to control cowpea aphid. Synergism and biochemical studies suggested that resistance is multifactorial. Esterase is the main metabolic enzyme contributing in chlorpyrifos-methyl resistance followed by oxidases but to a lesser degree. Moreover, GSTs plays a marginal role in resistance. Results indicate that careful selection and rotational use of non-cross-resistant insecticides should result in the satisfactory control of field populations of A. craccivora. Accordingly, an effective resistance management program is necessary to combat resistance development in A. craccivora. 


\section{References}

Abbott W. 1925. A method of computing the effectiveness of an insecticide. Journal of Economic Entomology 18 (2): 265-267. DOI: https://doi.org/10.1093/jee/18.2.265a

Abdallah I.S., Abou-Yousef H.M., Fouad E.A., Kandil M.A. 2016. The role of detoxifying enzymes in the resistance of the cowpea aphid (Aphis craccivora Koch) to thiamethoxam. Journal of Plant Protection Research 56 (1): 67-72. DOI: https://doi.org/10.1515/jppr-2016-0010

Andrew R.J., Silver H., Van Emden F., Battersby M. 2006. A biochemical mechanism of resistance to pirimicarb in two glasshouse clones of Aphis gossypii. Pest Management Science 43 (1): 21-29. DOI: 10.1002/ps.2780430104

Anonymous 2009. Arthropod pesticide resistance database http://www.pesticideresistance. org/search/1.

Cao C.W., Zhang J., Gao X.W., Liang P., Guo H.L. 2008. Overexpression of carboxylesterase gene associated with organophosphorus insecticide resistance in cotton aphid, Aphis gossypii (Glover). Pesticide Biochemistry and Physiology 90: 175-180. DOI: https://doi.org/10.1016/j. pestbp.2007.11.004

Costa L.G. 2006. Current issues in organophosphate toxicology. Clinica Chimica Acta 366 (1-2): 1-13. DOI: 10.1016/j. cca.2005.10.008

Criniti A., Mazzoni E., Cassanelli S., Cravedi P., Tondelli A., Bizzaro D., Manicardi G.C. 2008. Biochemical and molecular diagnosis of insecticide resistance conferred by esterase, MACE, kdr and super kdr based mechanisms in Italian strains of the peach potato aphid, Myzus Persicae (Sulzer). Pesticide Biochemistry and Physiology 90 (3): 168-174. DOI: https://doi.org/10.1016/j. pestbp.2007.11.005

Devonshire A.L. 1977. The properties of a carboxylesterase from the peach potato aphid, Myzus persicae (Sulz.) and its role in conferring insecticides resistance. Biochemical Journal 167: 675-683. DOI: $10.1042 / b j 1670675$

El-Ghareeb M., Nasser M.A.K., El-Sayed A.M.K., Mohamed G.A. 2002. Possible mechanisms of insecticide resistance in cowpea aphid, Aphis craccivora (Koch). The role of general esterase and oxidase enzymes in insecticide resistance of cowpea. The First Conference of the Central Agricultural Pesticide Laboratory, 3-5 September 2: 635-649.

Finney D. 1971. Probit Analysis: A Statistical Treatment of the Sigmoid Response Curve, 3rd ed. Cambridge University Press, London, $333 \mathrm{pp}$.

Fouad E.A., Abou-Yousef H.M., Abdalla I.S., Kandil M.A. 2016. Resistance monitoring and enzyme activity in three field populations of cowpea aphid (Aphis craccivora) from Egypt. Crop Protection 81: 163-167. DOI: https://doi. org/10.1016/j.cropro.2015.12.015
Guo Y.C., Zhang S.X., Zhao L.J., Chu C.F. 1996. Studies on resistance trends of cotton aphid and cotton bollworm to fenvalerate in field. Acta Agriculturae Universitatis Henanensis 30 (3): 284-287.

Habig W.H., Pabst M.J., Jakoby W.B. 1974. Glutathione-S-transferases: The first step in mercapturic acid formation. Journal of Biological Chemistry 249 (22): 7130-7139.

Kandil M.A., Abdallah I.S., Abou-Yousef H.M., Abdallah N.A., Fouad E.A. 2017. Mechanism of resistance to pirimicarb in the cowpea aphid, Aphis craccivora. Crop Protection 94: 73-177. DOI: https://doi.org/10.1016/j.cropro.2016.12.020

Kandil M.A., Radwan E.M.M., Swelam E.S.H., El-Deeb W.M.H., Mokbel E.M.S. 2013. Characterization and possible mechanisms of acetamiprid resistance in the cowpea aphid, Aphis craccivora (Koch). Bulletin of the Entomological Society of Egypt 90: 1-13.

Laamari M., Khelfa L., Coeur d'Acier A. 2008. Resistance source to cowpea aphid (Aphis craccivora Koch) in broad bean ( Vicia faba L.) Algerian landrace collection. African Journal of Biotechnology 7 (14): 2486-2490.

Lee S.E., Lees M. 2001. Biochemical mechanisms of resistance in strains of Oryzaephilus surinamensis (Coleoptera: Silvanidae) resistant to malathion and chlorpyrifos-methyl. Journal of Economic Entomology 94 (3): 706-713. DOI: https://doi.org/10.1603/0022-0493-94.3.706

Mokbel E.M.S., Mohamed A.I. 2009. Development of resistance in field strain of Aphis craccivora to the dinotefuran insecticides from the new class neonicotinoids and its effect on some enzymes content. Egyptian Academic Journal of Biological Sciences 1 (1): 65-69.

Mokbel E.M.S. 2015. Prediction of resistance and its stability of cowpea aphid, Aphis craccivora (Koch) to chlorpyrifos-methyl. Egyptian Scientific Journal of Pesticides 1 (4): 24-29.

Moores G.D., Gao X., Denholm I., Devonshir A.L. 1996. Characterization of insensitive acetylcholinesterase in insecticide resistant cotton aphids, Aphis gossypii Glover (Homoptera: Aphididae). Pesticide Biochemistry and Physiology 56 (2): 102-110. DOI: https://doi.org/10.1006/pest.1996.0064

Suzuki K., Hama H., Konno Y. 1993. Carboxylesterase of the cotton aphid, Aphis gossypii Glover (Homoptera: Aphididae), responsible for fenitrothion resistance as a sequestering protein. Applied Entomology and Zoology 28 (4): 439-450.

Van Asperen K. 1962. A study of housefly esterases by means of a sensitive colorimetric method. Journal of Insect Physiology 8 (4): 401-414. DOI: https://doi.org/10.1016/00221910(62) $90074-4$

Wang K.Y., Liu T.X., YU C.H., Jiang X.Y., Yi M.Q. 2002. Resistance of Aphis gossypii (Homoptera: Aphididae) to fenvalerate and imidacloprid and activities of detoxification enzymes on cotton and cucumber. Journal of Economic Entomology 95 (2): 2-11. DOI: https://doi.org/10.1603/0022-0493-95.2.407 